American J. of Engineering and Applied Sciences 3 (1): 83-89, 2010

ISSN 1941-7020

(C) 2010 Science Publications

\title{
Comparative Study of Different Underfill Material on Flip Chip Ceramic Ball Grid Array Based on Accelerated Thermal Cycling
}

\author{
${ }^{1,3}$ Z. Kornain, ${ }^{1}$ A. Jalar, ${ }^{2}$ N. Amin, ${ }^{3}$ R. Rasid and ${ }^{4}$ C.S. Foong \\ ${ }^{1}$ Institute of Microengineering and Nanoelectronics, University Kebangsaan Malaysia, \\ 43600 UKM Bangi, Selangor Darul Ehsan, Malaysia \\ ${ }^{2}$ Department of Electrical, Electronics and System, University Kebangsaan Malaysia, \\ 43600 UKM Bangi, Selangor Darul Ehsan, Malaysia \\ ${ }^{3}$ School of Applied Physics, University Kebangsaan Malaysia, \\ 43600 UKM Bangi, Selangor Darul Ehsan, Malaysia \\ ${ }^{4}$ Freescale Semiconductor, Free Industrial Zone Sungai Way, \\ 47300 Petaling Jaya Selangor, Malaysia
}

\begin{abstract}
Problem statement: This study mainly to study the effect of several commercial underfill materials to the reliability of HiCTE Flip Chip Ceramic Ball Grid Array (FC-CBGA) package due to Accelerated Thermal Cycling (ATC) effect. Approach: The warpage condition of package, die back stress, interfacial die shear stress, and solder bump fatigue for different commercial underfills were assessed and compared via a commercial Finite Element Analysis (FEA) under JEDEC Standard of ATC. The thermo-mechanical properties of underfills for simulation were obtained by using Thermal Mechanical Analyzer (TMA) and Dynamic Mechanical Analyzer (DMA). The actual package of HiCTE FC-CBGA were assembled with those underfill materials and underwent ATC to be compared with FEA result. Results: The results from FEA and experimental were discussed to characterize the performance of each underfill material. The results of this study indicate that the underfill materials investigated, those with a glass transition temperature (Tg) and a Young s modulus of approximately above $105^{\circ} \mathrm{C}$ and 8-9 GPa, respectively, were appropriate for HiCTE FC-CBGA with high lead solder bumps. Conclusion: The result from FEA analysis and ATC reliability test found that the underfill materials with high and medium low Young's modulus has high reliability in FC-CBGA package.
\end{abstract}

Key words: Ceramic, FC-CBGA, FEA, reliability thermo-mechanical, stress

\section{INTRODUCTION}

To meet the strict demands for smaller product size, lighter weight, and higher interconnection densities in electronics packaging, flip chip device have been developed. The reliability of these packages can be improved significantly with the use of underfill materials (Suryanarayana et al., 1993). The necessity of using an underfill for improving flip chip device reliability is well documented (Chen et al., 2006; Paquet et al., 2006). Underfill can improve the reliability life of flip-chip device as much as ten folds which provided environmental protection to the device, and to distribute the stress imposed by Coefficient Thermal Expansion (CTE) mismatch between silicon chip and substrate. By using an underfill material, the stress on the solder bumps during temperature cycling has been dispersed over the area of device. Thus, the stress on the device can be reduced and the reliability of the device can be enhanced (Xuefeng et al., 2009; Lau et al., 2000; Fan et al., 2001).

To some semiconductor manufacturers, the current study of new underfill material for ceramic flip chip package becomes a matter of great concern since the current material is giving much trouble to the reliability of package such as solder bump crack and underfill delamination after thermal cycle loading.

Even though ceramic substrate is costly material compared with organic substrate but due to its suitability for high speed device, it still applicable in current industry.

In many studies, to presume the effect of underfill properties towards the reliability of flip-chip package, the application of Finite Element Analysis (FEA) tool

Corresponding Author: Azman Jalar, Institute of Microengineering and Nanoelectronics,

University Kebangsaan Malaysia, 43600 UKM Bangi, Selangor Darul Ehsan, Malaysia

Tel: +60-3-89216996 Fax: +60-3-89216863 
was extensively used and in order to verify the simulation result, the experimental work have been done by conducting the thermal stress loading upon the real package (Yi et al., 2000; Kar and Lo, 2006; Solid State Technology Association (JEDEC), 2004; Zhao and Tay, 2003).

In this study, the effect of different commercial underfill material towards the reliability of HiCTE Flip Chip Ceramic Ball Grid Array (FC-CBGA) under accelerated temperature cycling (ATC) were studied. Dynamic Mechanical Analyser (DMA) and Thermal Mechanical Analyser (TMA) analysis were conducted in-house to obtain the thermo-mechanical properties of underfill such as glass transition (Tg), Young's modulus (E), Coefficient Thermal Expansion (CTE). FEA commercial software, ANSYS ${ }^{\circledR}$, used to predict the effect of each underfill material to the package warpage condition, die back stress, die shear stress and solder bump fatigue. The result from FEA was verified by conducting ATC test $\left(-40\right.$ to $\left.125^{\circ} \mathrm{C}\right)$ upon the actual package of HiCTE FC-CBGA according to JEDEC JESD22-A104 condition G.

\section{MATERIALS AND METHODS}

Underfill material properties: Five different types of new commercial underfills (namely as UFA, UFB, UFC, UFD, UFE) from five suppliers were selected based on their suitability for medium large die and fine pitch cu/low-k HiCTE FC-CBGA.

Due to consistent test method compared with data obtained from suppliers, material analysis using TMA and DMA were conducted in-house for obtaining underfill thermomechanical properties (Yi et al., 2000). CTE and Tg of cured underfill were measured using a TA Instrument TMA. The cylindrical cured underfill with $4.7 \mathrm{~mm}$ height was heated from -50 to $260^{\circ} \mathrm{C}$ with a heating rate of $10^{\circ} \mathrm{C} \mathrm{min}^{-1}$.

Young's modulus of cured underfill were determined using TA Instrument DMA operated in rectangular tension mode. Cured underfill grinded into cubes with dimension about $15.0 \times 2.5 \times 1.20 \mathrm{~mm}$ and heated from -50 to $210^{\circ} \mathrm{C}$ using $10^{\circ} \mathrm{C} \mathrm{min}{ }^{-1}$ heating rate. For underfill materials, the definition of the mean or effective CTE was used for the implementation in simulation is described by the following equation (Kar and Lo, 2006):

$$
\text { Effect.CTE }=\frac{\left(\mathrm{Tg}-\mathrm{T}_{1}\right) \mathrm{CTE}_{1}+\left(\mathrm{T}_{2}-\mathrm{Tg}\right) \mathrm{CTE}_{2}}{\mathrm{~T}_{2}-\mathrm{T}_{1}}
$$

where, $T_{2}$ is the stress-free or reference temperature of the component being modelled. As $\mathrm{T}_{1}$ was $-40^{\circ} \mathrm{C}$ and $\mathrm{T}_{2}$ was the underfill's curing temperature $\left(\sim 165^{\circ} \mathrm{C}\right)$, the effective CTE for underfill were calculated (Kar and Lo, 2006). The thermo-mechanical properties of all components in the package are shown in Table 1 and 2.

FEA modelling: To observe the effects toward warpage package condition, die back stress, interfacial die stress and underfill strain energy density, FEA analysis were performed for global package without bumps. Meanwhile to observe the effect toward solder bump fatigue life, FEA analysis was performed for package slice model with two outer-most bumps. Both sections were conducted using FEA commercial software ANSYS.

Global package model: The dimensions of the chip under study were $15.0 \times 12.0 \times 0.75 \mathrm{~mm}$ and fully populated with high lead solder bumps (Pb90Sn10) with stand off $65 \mu \mathrm{m}$. The dimension of the HiCTE ceramic substrate was $33.0 \times 33.0 \times 1.2 \mathrm{~mm}$ and the underfill fillet height is considered as $100 \%$. For the thermal stress effect in respect to the die back or corner, underfill and die interface and package warpage, analysis was carried out without bumps where linear elastic, time and temperature independent properties were assumed for all materials (Kar and Lo, 2006). Neglecting the bumps will not affect that much to the global model results. Due to symmetry, a quarter symmetric global model was used with corresponding boundary conditions and analyzed under accelerated temperature cycling (Kar and Lo, 2006). Figure 1 shows the generated mesh of the model for global package.

Table 1: Material properties for components of FC-CBGA

\begin{tabular}{lccl}
\hline Component $\left(\mathrm{ppm} /{ }^{\circ} \mathrm{C}\right)$ & $\mathrm{E}(\mathrm{GPa})$ & $\mathrm{CTE}$ & Poisson ratio \\
\hline Silicon die & 131.50 & 2.80 & 0.27 \\
Solder bump $(\mathrm{Pb} 90 \mathrm{Sn} 10)$ & 27.30 & 24.50 & 0.35 \\
HiCTE ceramic substrate & 85.30 & 14.00 & 0.30 \\
Underfill & \multicolumn{3}{c}{ Refer to Table 2 } \\
\hline
\end{tabular}

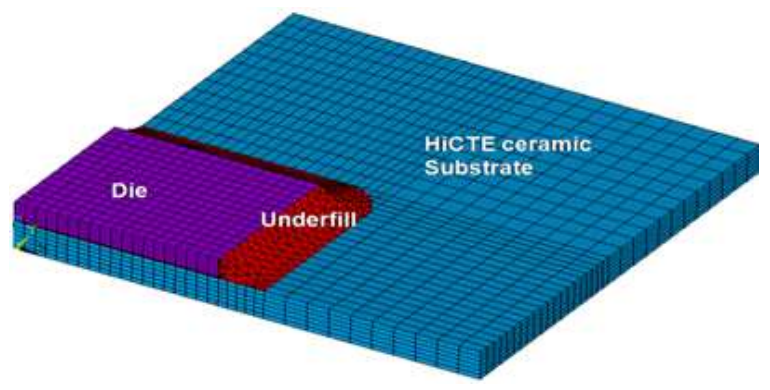

Fig. 1: A quarter symmetric model for HiCTE FPCBGA 
Am. J. Engg. \& Applied Sci., 3 (1): 83-89, 2010

Table 2: The thermo-mechanical properties for each underfill obtained from DMA and TMA analysis at $-40^{\circ} \mathrm{C}$

\begin{tabular}{lllccrr}
\hline Supplier & Material code & $\begin{array}{l}\text { Curing temperature }\left({ }^{\circ} \mathrm{C}\right) \\
\text { /time }(\mathrm{min})\end{array}$ & $\begin{array}{l}\text { Young modulus } \\
\mathrm{E}(\mathrm{GPa})\end{array}$ & $\begin{array}{l}\text { CTE 1/CTE } 2 \\
\left(\mathrm{ppm} /{ }^{\circ} \mathrm{C}\right)\end{array}$ & $\begin{array}{c}\text { Eff. CTE } \\
\left(\mathrm{ppm} /{ }^{\circ} \mathrm{C}\right)\end{array}$ \\
\hline Hitachi & UFA & $165^{\circ} \mathrm{C} / 90$ & 10.20 & $28.60 / 93.20$ & 43.60 & 117.30 \\
Nagase & UFB & $160^{\circ} \mathrm{C} / 120$ & 8.20 & $34.80 / 126.20$ & 63.40 & 97.50 \\
Namics & UFC & $165^{\circ} \mathrm{C} / 90$ & 11.60 & $34.40 / 122.80$ & 79.90 & 59.50 \\
Henkel & UFD & $165^{\circ} \mathrm{C} / / 90$ & 8.90 & $25.40 / 85.40$ & 42.70 & 105.80 \\
Ablestik & UFE & $165^{\circ} \mathrm{C} / 90$ & 12.00 & $29.30 / 92.80$ & 48.70 & 102.40 \\
\hline
\end{tabular}

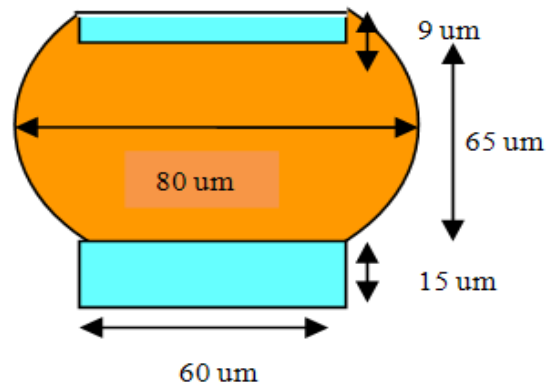

Fig. 2: A schematic of solder bump dimension for FEA

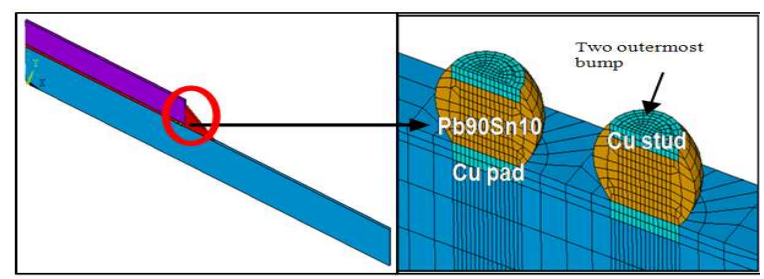

Fig. 3: A 3D slice model with mirror symmetry for two outermost bump

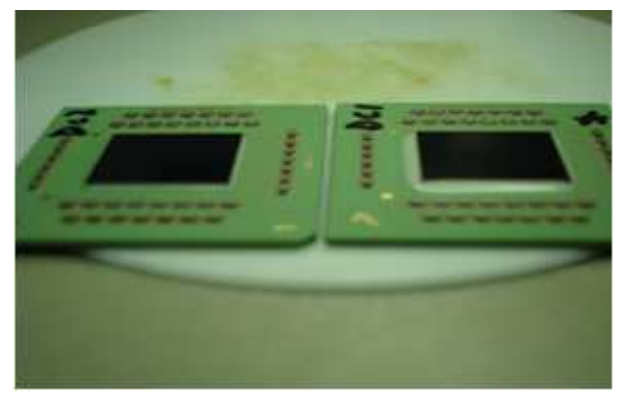

Fig. 4: HiCTE FC-CBGA package after assembly and cured

Temperature loading of the simulation based on JEDEC JESD22-A104 condition G. The dwell or ramp period was 15 minutes and the temperature load was ramped up and down between the high of $125^{\circ} \mathrm{C}$ and the low of $-40^{\circ} \mathrm{C}$ with an increment of $10^{\circ} \mathrm{C}$ for each load sub-step. The thermal load application was assumed to be uniform throughout the FEA model (Solid State Technology Association (JEDEC), 2004).
Solder joint fatigue model: Viscoplastic finite-element simulation methodologies were utilized to predict solder ball joint reliability of the package under ATC. Due to the complex physics that encompass this type of non-linear transient finite element analysis, only a slice model with mirror symmetry and node-coupling boundary conditions were modelled in order to facilitate reasonable model run time (Zhao and Tay, 2003). Figure 2 shows a schematic geometry of the high lead bumps. The utilization of slice model as shown in Fig. 3 assures that a worst-case situation was simulated where two rows of bumps near die corners were modelled based on Darveaux's modified Anand's (Zahn, 2000). The explanations on solder joint fatigue life prediction methodology by Darveaux can be referred elsewhere (Xiaoyan and Wang, 2006; Darveaux, 2000).

Accelerated temperature cycle reliability test: In order to compare with FEA result, the actual package was tested under ATC. Package dimension was similar to the package size for FEA. The package was a high speed and high power microprocessor device for telecommunication application. The die was developed with CMOS $90 \mathrm{~nm}$ technology, internally engineered low-k dielectric and Polyimide (PI) passivation. Underfill was capillary dispensed to into the gap between die and substrate using Asymtek DS-9000 Underfill Dispenser with preheating temperature at $100^{\circ} \mathrm{C}$ and cured at certain temperature and time as shown in Table 2. The cured package then subjected to 500 and 1000 cycles of -40 to $125^{\circ} \mathrm{C}$ ATC following JEDEC JESD22-A104 condition G (Solid State Technology Association (JEDEC), 2004). Fig. 4 shows the condition of package after assembly and cured. Package integrity after thermal stressing was assessed using C-mode Scanning Acoustic Microscopy (CSAM) and cross sectioning inspection.

\section{RESULTS}

Finite element analysis: Package warpage comparison and die back stress: During thermal cycle loading at $40 \mathrm{C}$, the substrate contracts more than the die and bends into a convex shape causing a "frowning face" warpage (Wenge et al., 1998). Fig. 5 shows the warpage of global package for UFA and Fig. 6 shows the comparison of warpage value between all underfills. 


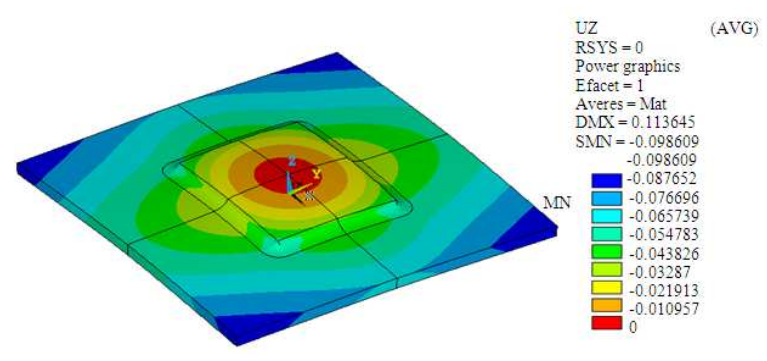

Fig. 5: A FEA result of package warpage for UFA at $40^{\circ} \mathrm{C}$

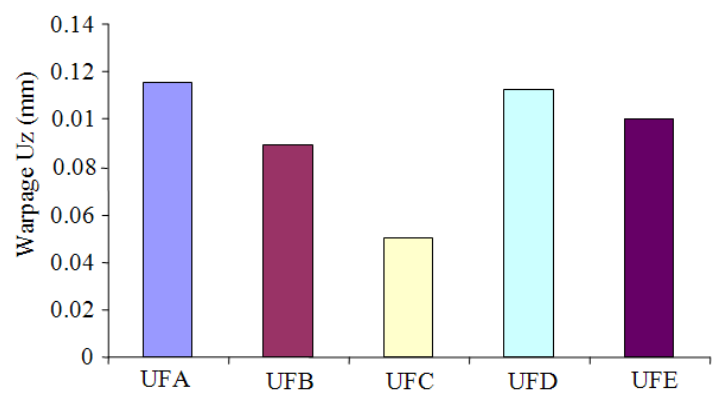

Fig. 6: Warpage comparison for different underfill

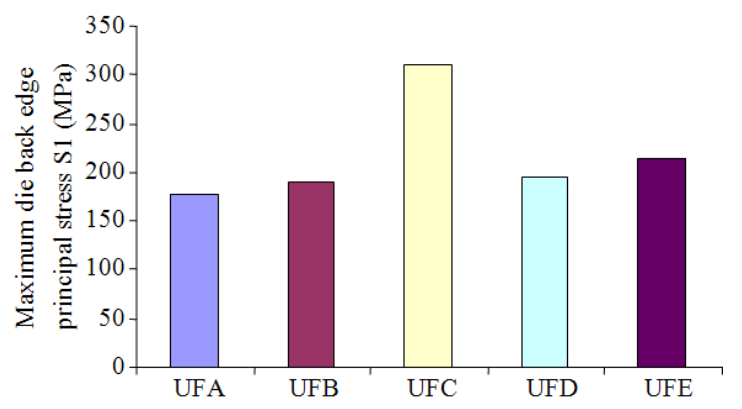

Fig. 7: Comparison of maximum die back stress for different underfill

The result of maximum principle stress for die back as depicted in Fig. 7 shows that the UFC has given highest maximum stress at the die edge. Fig. 8 shows the contour of die back stress for UFE demonstrating the maximum stress concentrates at the area die's edge.

Die shear stress: High shear stress at $-40^{\circ} \mathrm{C}$, induced between underfill and die interface lead to the delamination in interfacial area and delaminate the fragile layer of low-k ILD located in the die (Yuko et al., 2002). Figure 9 shows that the highest shear stress can be observed in the area of interface between die and underfill and concentrated in the corner of the die. Figure 10 shows the comparison of die corner stress at maximum value for different underfill materials.

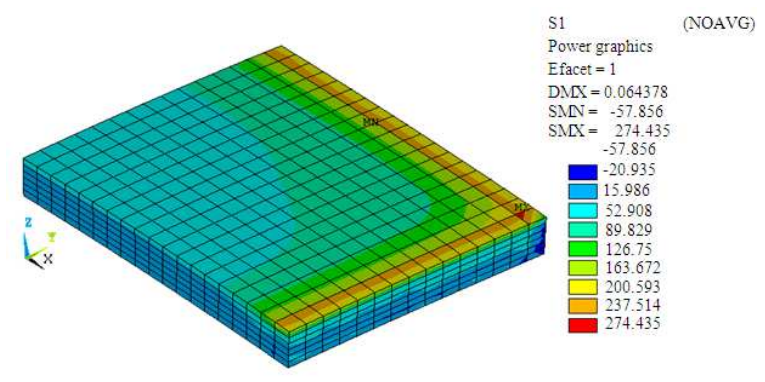

Fig. 8: A contour of principle stress at die for UFA at $-40^{\circ} \mathrm{C}$

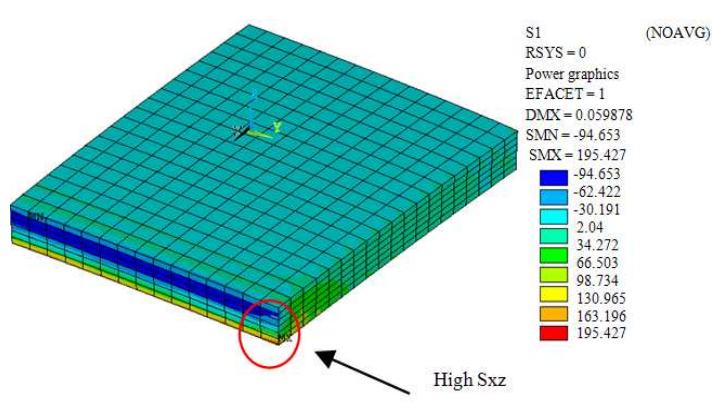

Fig. 9: Highest shear stress occurred at die's interfacial

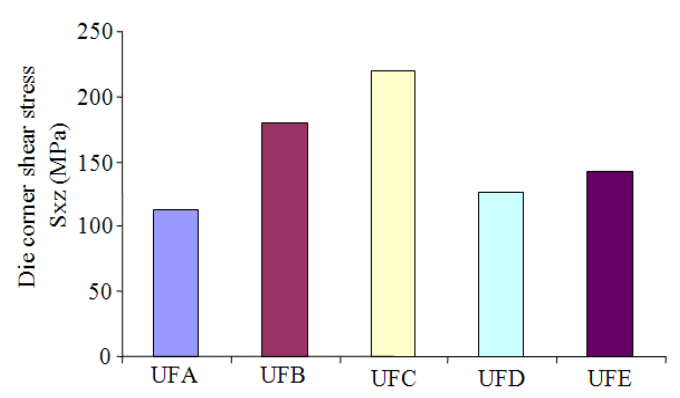

Fig. 10: Comparison of maximum die corner shear stress for different underfill

Solder bump fatigue life: The Von Mises stress (Sxy) and inelastic strain (W) after second cycle of thermal loading for UFE are exhibited in Fig. 11a and b respectively while Fig. 11c shows the contour of solder plastic work density after second cycle of ATC at $-40^{\circ} \mathrm{C}$ for UFE and the outermost solder bump has it maximum value. The comparison among underfill for its effect to solder fatigue life is shown in Fig. 12.

Package under ATC: The size of the samples for each underfill type was 30 based on industry requirement. Table 3 lists the reliability test results with all underfills. Figure 13 shows the sample of failure condition captured by C-SAM after ATC 1000 cycles. Figure 14 shows the cross-section of three outermost bumps for the failed sample of UFC. 

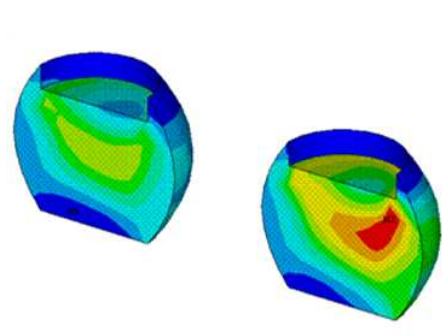

(a)
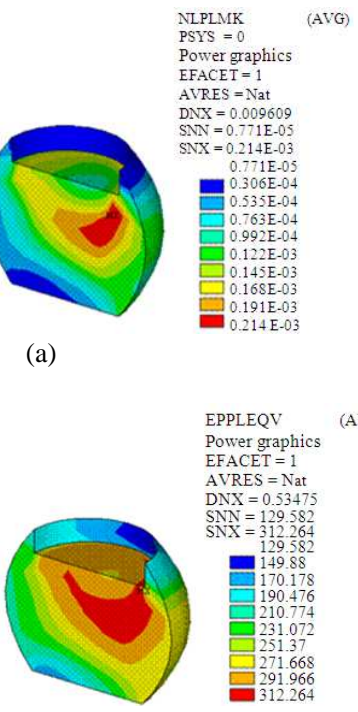

(b)
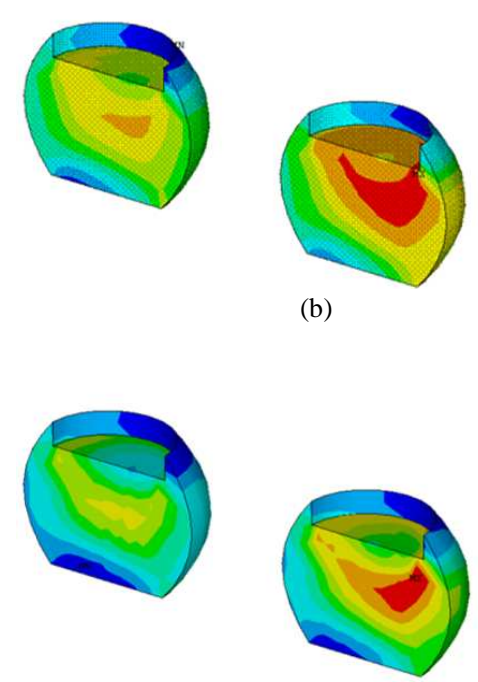

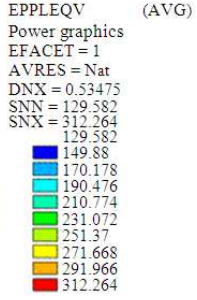

EPPLEQV

(AVG) Power graphics EFACET $=1$ $\mathrm{DNX}=0.53475$ SNN $=0.125 \mathrm{E}-06$

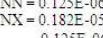

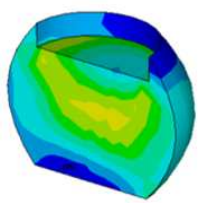

(c)

Fig. 11: (a) A contour of solder von mises stress in 2nd cycle at $-40^{\circ} \mathrm{C}$ for UFE, (b) A contour of von mises elastic strain in 2 nd cycle at $-40^{\circ} \mathrm{C}$ for UFE, (c) A Contour of solder plastic work density after second cycle for UFE

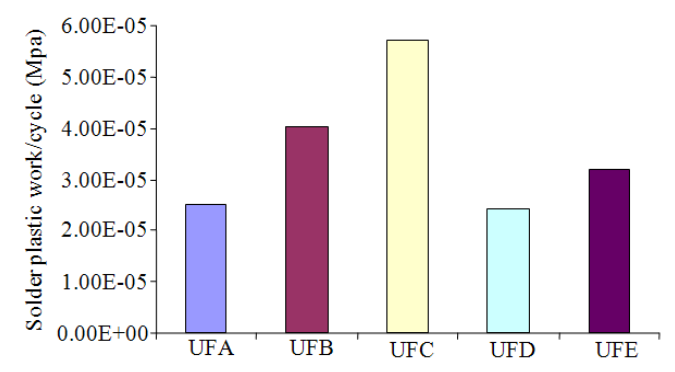

Fig. 12: Comparison of solder fatigue life for different underfills after $2^{\text {nd }}$ cycle

Table 3: Result of ATC test for each underfill material. All underfill exhibits no voids and delamination before ATC test

\begin{tabular}{llllll}
\hline Underfill & UFA & UFB & UFC & UFD & UFE \\
\hline Before ATC & $0 / 30$ & $0 / 30$ & $0 / 30$ & $0 / 30$ & $0 / 30$ \\
ATC 500 cycles & $0 / 30$ & $4 / 30$ & $8 / 30$ & $0 / 30$ & $4 / 30$ \\
ATC 1000 cycles & $0 / 30$ & $6 / 30$ & $20 / 30$ & $0 / 30$ & $4 / 30$ \\
\hline
\end{tabular}

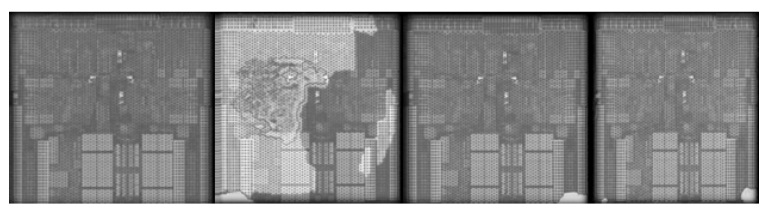

(a)

(b)

(c)

(d)

Fig. 13: CSAM photo for after ATC 1000 cycles, (a) Ackage condition for UFA and UFD without delamination, (b) Severe delamination condition for UFC, (c) Delamination condition for UFB, (d) Delamination condition for UFE

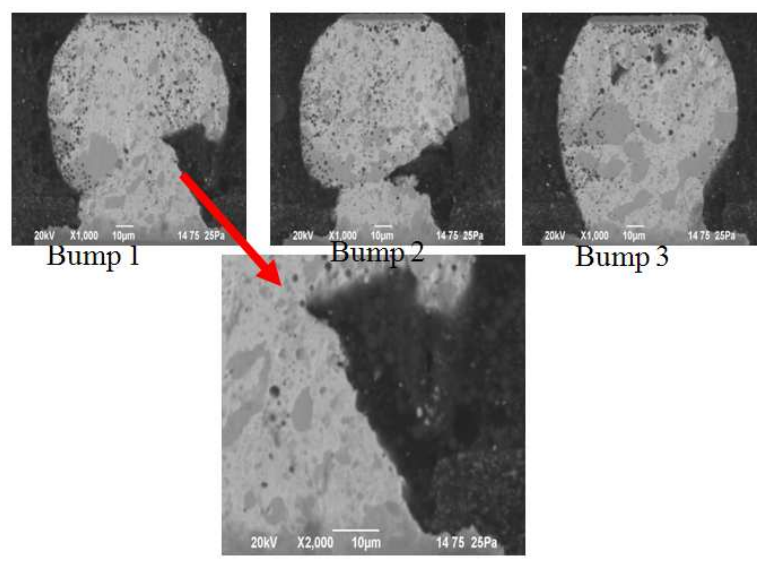

Fig. 14: Condition of solder crack in three outermost bump (left side of package) for UFC

\section{DISCUSSION}

Finite element analysis: Package warpage comparison and die back stress: Fig. 6 clearly shows that package with UFC has lowest warpage compared with others. Package with UFA and UFD have highest warpage value in the list. This condition can be attributed to the value of underfill's $\mathrm{Tg}$ where the higher the $\mathrm{Tg}$ the higher the warpage. This result agreed with work performed by Wenge et al. (1998). As conclusion, the lower the warpage the better the reliability of the package can be achieved. It was reported that the higher the stress, the die edge crack tends to occur with higher probability (Fan et al., 2001). This agreed with the result obtained in Fig. 7. Therefore, UFA has the lowest risk to have the die edge crack. Figure 8 shows the area of highly stress concentration at die's edge where it can contribute to crack.

Die shear stress: At temperature of $-40^{\circ} \mathrm{C}$, high shear stress can be induced between underfill and die interface lead to the delamination in interfacial area and 
delaminate the fragile layer of low-k ILD located in the die (Yuko et al., 2002). This situation was of high risk to interface delamination due to high modulus and stiffness of the material (Yuko et al., 2002). UFA and UFD were predicted as the favorable candidate giving lowest impact to delamination since these material having lower modulus under at $-40^{\circ} \mathrm{C}$ during thermal cycling.

Solder bump fatigue life: The solder joint viscoplastic strain energy density accumulated per thermal cycle was used to evaluate the fatigue life of bump interconnects and usually referred as the amount of "plastic work" accumulated per cycle (Zhao and Tay, 2003; Zahn, 2000; Xiaoyan and Wang, 2006; Darveaux, 2000). It clearly shown in Fig. 11 a and b that the maximum shear stress and inelastic strain energy density occurs near the outermost edge of the solder bump. The lower the inelastic strain energy density accumulated per TC cycle $(\Delta \mathrm{W})$, the longer the thermal fatigue life of the solder joint (Zahn, 2000). The result in Fig. 12 shows the UFA, UFD and UFE generated the lower solder work per cycle as compared with UFB and UFC. This condition induced lower solder fatigue life for all materials except UFC. According to previous researcher (Xiaoyan and Wang, 2006), low Tg has possible to induce solder bump crack, while high $\mathrm{Tg}$ can protect the bump from failure.

Package under ATC: Normally, interface delamination between die and underfill were found as dominant failure in sample after ATC test (Chen et al., 2006). The open failure samples were extremely found in UFC after ATC 500 cycles and 1000 cycles with highest failure rate of $8 / 30$ and 20/30 respectively as stated in Table 3. Meanwhile a few open failures found in UFD and UFE after 500 and 1000 cycles. However, UFA and UFB passed ATC 500 and 1000 cycles without any failure. This outcome verified result in die shear stress using FEA simulation which UFC has possibility to generate highest die stress and induced delamination particularly at corners of the die edge. In this case UFA and UFD have lowest risk upon delamination. The delamination in the package with UFB, UFC and UFE were found to be due to poor adhesion and high die shear stress(Suryanarayana et al., 1993; Chen et al., 2006). In principle, the package with UFC has the lowest thermo-mechanical reliability because it has low Tg and high CTE value (Lau et al., 2000). In the other hand, the package with the underfill material of high $\mathrm{Tg}$ and low CTE value allowed the thermal and mechanical stresses to be well absorbed and distributed in the package (Chen et al., 2006).
As depicted in Fig. 13, most of delamination occurred in the die's corner. Package with UFC shows severe delamination at die corners as well as interface of underfill and solder mask of plastic substrate. This also agreed with the simulation result discussed in die shear stress section. To investigate failed samples for solder bump, the package was subjected to crosssection and inspection under Scanning Electronic Microscope (SEM) as shown in Fig. 14. The solder bump cracking was found at the outermost bump location owing to the package with UFC has higher bump shear stress fatigue than others. Outermost bump 1 and 2 show crack while no crack occurred at the third bump.

No solder bump crack were found for the package with others underfill type. This observation agreed with prediction performance for solder fatigue as depicted in Fig. 12. UFC was induced higher die shear stress at the die corner than others. This implies the adhesive force between die and underfill was not good enough (Chungpaiboonpatana and Shi, 2005). This was agreed with simulation result presented in Fig. 8 where UFC had the highest die corner shear stress.

For die back observation, no crack event was observed since all samples has low fillet height after cured. The die back stress was more influenced by fillet geometry even though underfill material have some effect too. The effect from underfill material was reported as not critical factor to die back reliability (Fan et al., 2001). The fillet height and width affect the die back stress and possible to induce the cracking in die edge.

\section{CONCLUSION}

A study on the effect of different thermomechanical properties of underfill to the reliability of HiCTE Flip Chip Ceramic Ball Grid Array (FC-CBGA) package due to Accelerated Thermal Cycling (ATC) was presented in this paper. It was found that UFC which supplied from demonstrated worst impact to solder crack and delamination when thermal cycling stress loaded into the package due to low Tg, high CTE and high Young's modulus. Two favourable candidates which demonstrated good reliability after using FEA analysis and reliability test were UFA and UFD. Both materials produced no delamination and solder bump crack after ATC reliability test. The material with high $\mathrm{Tg}$ and medium low of Young's modulus resulting good protection to solder bump crack and die/underfill interfacial failure. This study suggested that the underfill materials with a glass transition temperature ( $\mathrm{Tg}$ ) and a Young's modulus of approximately above $105^{\circ} \mathrm{C}$ and 8-9 $\mathrm{GPa}$, respectively, were suitable 88 
properties value in order to pass the industry standard of ATC test for HiCTE FC-CBGA.

\section{ACKNOWLEDGEMENT}

The researchers would like to express their appreciation to Freescale Semiconductor for their support in experimental job and heartfelt gratitude to $\mathrm{Dr}$ Kar Shim Wei from Freescale Semiconductor for his consultation to the modeling work. Also would like to thank Microscopy Lab of UKM for their help in cross section and SEM analysis.

\section{REFERENCES}

Chen, K.M., D.S. Jiang, N.H. Kao and J.Y. Lai, 2006. Effects of underfill materials on the reliability of low-k flip chip packaging. Microelect. Reliabil., 46: 155-163. DOI: 10.1016/j.microrel.2005.05.001

Chungpaiboonpatana, S. and F.G. Shi, 2005 Advanced HiCTE ceramic flip-chipping of $90 \mathrm{~nm} \mathrm{Cu} / \mathrm{low}-\mathrm{k}$ device: A novel material, package structure, and process optimization study. J. Elect. Mater., 34: 977-993.

http://cat.inist.fr/?aModele $=$ afficheN\&cpsidt $=16947867$

Darveaux, R., 2000. Effect of simulation methodology on solder joint crack growth correlations. Proceeding of the 50th IEEE Electronics Component and Technology Conference, May 2124, IEEE Xplore Press, Las Vegas, USA., pp: 1048-1058. DOI: 10.1109/ECTC.2000.853299

Fan, X.J., H.B. Wang and T.B. Lim, 2001. Investigation of underfill delamination and cracking in flip chip module under thermal cycle loading. IEEE. Trans. Comput. Pack. Technol., 24: 84-90. DOI: 10.1109/6144.910806

Kar, W.S. and W.Y. Lo, 2006. Solder fatigue modeling of flip-chip bumps in molded packages. Proceeding of the 31th International Electronic Manufacturing Technology, IEEE Xplore Press, Nov. 8-6, Putrajaya, Kuala Lumpur, pp: 109-114. DOI: 10.1109/IEMT.2006.4456441

Lau, J.H., W.S. Lee and C. Chang, 2000. Effects of underfill material properties on the reliability of solder bumped flip chip on board with imperfect underfill encapsulants. IEEE. Trans. Comput. Pack. Technol., 23: 323-333. DOI: 10.1109/6144.846771

Paquet, M., M. Gaynes, E. Duchesne, D. Questad, L. Belanger and M. Sylvestre, 2006. Underfill selection strategy for $\mathrm{pb}$-free, low-K and fine pitch organic flip chip applications. Proceeding of the 56th Electronic Components and Technology Conference, IEEE Xplore Press, July 5-7, San Diego, USA., pp: 1595-1603. DOI: 10.1109/ECTC.2006.1645870
Solid State Technology Association (JEDEC), 2004. Joint industry standard: Temperature Cycling. JEDEC-JESD22-A104C May 2005, pp: 1-10.

Suryanarayana, D., T.Y. Wu and J.A. Varcoe, 1993. Encapsulants used in flip-chip packages. IEEE Trans. Comput. Hybrids Manufactur. Technol., 16: 858-862. http://cat.inist.fr/?aModele=afficheN\&cpsidt=4056611

Wang, L. and C.P. Wong, 2000. Recent advances in underfill technology for flip-chip, ball grid array, and chip scale package applications. Conference of International Symposium on Electronic Materials and Packaging, Nov. 30-Dec. 2, IEEE Xplore Press, Hong Kong, pp: 224-231. DOI: 10.1109/EMAP.2000.904159

Wenge, Z., D. Wu, B. Su, S.A Hareb, Y.C. Lee, and B.P. Masterson, 1998. The effect of underfill epoxy on warpage in flip chip assemblies. IEEE. Trans. Comput. Pack. Manufactur. Technol. A., 21: 323-328. http://ieeexplore.ieee.org/iel4/95/15246/00705481. pdf?arnumber $=705481$

Xiaoyan, L. and Z. Wang, 2006. Thermo-fatigue life evaluation of $\mathrm{SnAgCu}$ solder joints in flip chip assemblies. J. Mat Proces. Tech., 183: 6-12. DOI: 10.1016/j.jmatprotec.2006.09.010

Xuefeng, O., S.W. Hoa, Y.Y. Onga, L.C. Waia, K. Vaidyanathana and Y.K. Lim, 2009. Underfill Selection methodology for fine pitch Cu/low-k FCBGA packages. Microelect. Reliabil., 49: 150-162. http://cat.inist.fr/?aModele $=$ afficheN\&cpsidt $=21172778$

Yi, H. et al., 2000. Thermal characterization of an epoxy-based underfill material for flip chip packaging. Thermochimica Acta, 40: 1-8. http://cat.inist.fr/?aModele=afficheN\&cpsidt=1443851

Yuko, S., K. Harada and H. Fujioka, 2002. Study of package warp behavior for high-performance flipchip BGA. J. Microelect. Reliabil., 43: 465-471. DOI: 10.1016/S0026-2714(02)00294-9

Zahn, B.A., 2000. Comprehensive solder fatigue and thermal characterization of a silicon based multichip module package utilizing finite element analysis methodologies. Proceeding of 9th International ANSYS Conference and Exhibition, Aug. 28-30, Pittsburgh, USA., pp: 30-45. http://ansys.net/ansys/papers/bzahn00.pdf

Zhao, B. and A.A. Tay, 2003. Simulation of fatigue life of solder ball joints of an ultra-fine-pitch wafer level package. Proceeding of the 5th Electronics Packaging Technology Conference, Dec. 10-12, IEEE Xplore Press, Singapore, pp: 683-686. http://ieeexplore.ieee.org/xpl/freeabs_all.jsp?arnum ber $=1271606$ 